This item was submitted to Loughborough's Research Repository by the author.

Items in Figshare are protected by copyright, with all rights reserved, unless otherwise indicated.

\title{
Control-oriented dynamics analysis for electrified turbocharged diesel engines
}

\section{PLEASE CITE THE PUBLISHED VERSION}

http://dx.doi.org/10.4271/2016-01-0617

PUBLISHER

(C) SAE International

VERSION

VoR (Version of Record)

LICENCE

CC BY-NC-ND 4.0

\section{REPOSITORY RECORD}

Zhao, Dezong, Edward Winward, Zhijia Yang, John Rutledge, and Richard Stobart. 2017. "Control-oriented Dynamics Analysis for Electrified Turbocharged Diesel Engines”. figshare. https://hdl.handle.net/2134/24356. 


\section{Control-Oriented Dynamics Analysis for Electrified Turbocharged Diesel Engines}

\section{Dezong Zhao, Edward Winward, and Zhijia Yang}

Loughborough University

\section{John Rutledge}

Caterpillar Inc.

\section{Richard Stobart \\ Loughborough University}

CITATION: Zhao, D., Winward, E., Yang, Z., Rutledge, J. et al., "Control-Oriented Dynamics Analysis for Electrified Turbocharged Diesel Engines," SAE Technical Paper 2016-01-0617, 2016, doi:10.4271/2016-01-0617.

\begin{abstract}
Engine electrification is a critical technology in the promotion of engine fuel efficiency, among which the electrified turbocharger is regarded as the promising solution in engine downsizing. By installing electrical devices on the turbocharger, the excess energy can be captured, stored, and re-used. The electrified turbocharger consists of a variable geometry turbocharger (VGT) and an electric motor (EM) within the turbocharger bearing housing, where the EM is capable in bi-directional power transfer. The VGT, EM, and exhaust gas recirculation (EGR) valve all impact the dynamics of air path. In this paper, the dynamics in an electrified turbocharged diesel engine (ETDE), especially the couplings between different loops in the air path is analyzed. Furthermore, an explicit principle in selecting control variables is proposed. Based on the analysis, a model-based multi-input multi-output (MIMO) decoupling controller is designed to regulate the air path dynamics. The dynamics analysis and controller are successfully validated through experiments and simulations.
\end{abstract}

\section{Introduction}

Global countries are making stricter fuel efficiency legislation of ground vehicles driven by the increasing pressure on fuel consumption and environmental protection. The heavy duty vehicles (HDVs) contribute almost one quarter of the fuel consumption in transportation [1], and most of which are equipped with diesel engines due to their high thermal efficiency and high torque at low speeds. Engine electrical hybridization is a critical energy recovery technology in reducing $\mathrm{CO}_{2}$ emissions, which is mainly focused on the turbocharger. The VGT and EM both have the ability to manage the energy flows in the air path. When the turbine power exceeds the required compressor power, the extra mechanical power is recuperated by the EM to power other electrical accessories or stored in battery for later usage. On the other hand, when the available turbine power is less than the required compressor power, especially during transients, the EM accelerates the turbocharger to assist boosting. Since a third of fuel energy in internal combustion engines (ICE) is lost to the environment through the exhaust gas, the electrified turbocharger is seen as a promising solution in raising fuel efficiency of HDVs [2]].

The electrified turbocharger has attracted considerable development interest. Advances in power electronics have led to the development of ultra-high speed EM with the capacity of higher than 100,000 rpm, which is now available for use in turbochargers [3] . The mainstream diesel engine and turbocharger manufacturers have developed their own prototype electrified turbochargers $[\underline{4}, \underline{5}, \underline{6}]$. Investigations into the efficiency characterization of an electrified turbocharger through experiments with a heavy duty diesel engine have been made in $[\underline{7}, \underline{8}]$. All of the research results agree that the development of a promising multiinput multi-output (MIMO) control strategy is essential in exploring the maximum benefits of the electrified turbocharger.

The control of the ETDE is still in its infancy. In [6] the EM is controlled in an open loop manner. In [9]], the EM, VGT, and EGR valve are controlled independently without considering the couplings. This paper analyzes the dynamics of the ETDE and its impact on fuel economy. Furthermore, a model-based MIMO decoupling control strategy is proposed. The contributions of the paper are:

1. An explicit principle in selecting control variables for the control of ETDE is proposed. Physical analysis is also given to support this point. 
2. A model-based MIMO decoupling control framework is designed to regulate the air path dynamics, in dealing with internal couplings on actuators.

3. The proposed control strategy is successfully applied on a physical model for validation.

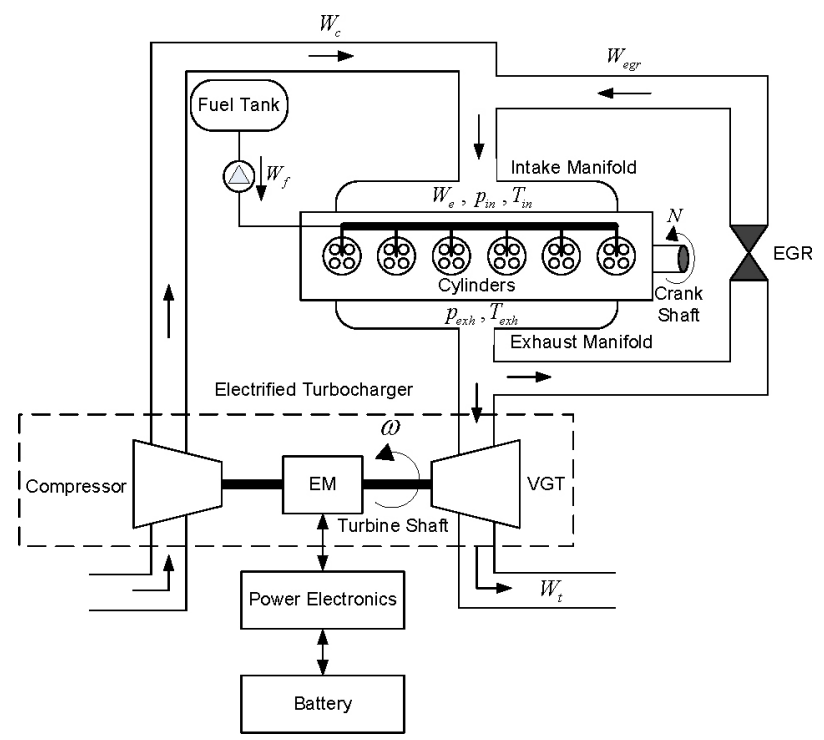

Figure 1. Electrified turbocharged diesel engine

\section{Electrified Turbocharged Diesel Engine Model}

In Table 1, the variables and related parameters of the ETDE illustrated in Fig. 1 are listed. A switched reluctance motor (SRM) is selected as the EM for it is an excellent option in extra-high speed applications thanks to its simple structure [10]. The EM can work in both assisting mode and generating mode. In assisting mode, the EM extracts energy from the battery to improve the engine transient response, or provide steady state boost pressure to enhance low speed torque. In generating mode, the additional turbine torque resulting from excess exhaust energy causes a power flow to the generator.

Ignoring the slow deviation of $T_{i n}$ and $T_{\text {exh }}$, the control-oriented mean value model of the engine air path is derived based on the conservation of mass and energy and the ideal gas law [11]:

$$
\begin{gathered}
\dot{p}_{i n}=\frac{R_{g} T_{i n}}{V_{i n}}\left(W_{c}+W_{e g r}-W_{e}\right), \\
\dot{p}_{e x h}=\frac{R_{g} T_{e x h}}{V_{e x h}}\left(W_{e}-W_{e g r}-W_{t}+W_{f}\right) .
\end{gathered}
$$

$W_{e}$ is the total mass flow rate from intake manifold to cylinders and modeled by the speed-density equation as

$$
W_{e}=\frac{\eta_{v} p_{i n} V_{d}}{120 T_{\text {in }} R_{g}} N
$$

$W_{\text {egr }}$ and $W_{t}$ can be modeled by standard orifice flow equations.
The dynamics of the turbocharger can be modeled as a first-order lag power transfer function with time constant $\tau$ :

$$
\dot{P}_{c}=\frac{1}{\tau}\left(P_{t}+P_{e m}-P_{b l}-P_{w l}-P_{c}\right) .
$$

\begin{tabular}{|c|c|}
\hline Variable & Description \\
\hline$N$ & Engine speed \\
\hline$T_{L}$ & Engine load \\
\hline$W_{f}$ & Engine fuelling rate \\
\hline$W_{c}$ & Compressor air mass flow rate \\
\hline$W_{e g r}$ & EGR mass flow rate \\
\hline$W_{e}$ & Engine total mass flow rate \\
\hline$W_{t}$ & Turbine gas mass flow rate \\
\hline$F_{1}$ & Burnt gas fraction, defined as $\frac{W_{e g r}}{W_{c}+W_{e g r}}$ \\
\hline$\lambda$ & In-cylinder air-fuel ratio, defined as $\frac{W_{c}}{W_{f}}$ \\
\hline$P_{C}$ & Compressor power \\
\hline$P_{t}$ & Turbine power \\
\hline$P_{e m}$ & EM power \\
\hline$p_{\text {in }}$ & Intake manifold pressure \\
\hline$p_{e x h}$ & Exhaust manifold pressure \\
\hline$p_{a m}$ & Ambient pressure \\
\hline$T_{\text {in }}$ & Intake manifold temperature \\
\hline$T_{e x h}$ & Exhaust manifold temperature \\
\hline$V_{\text {in }}$ & Intake manifold volume \\
\hline$V_{e x h}$ & Exhaust manifold volume \\
\hline$V_{d}$ & Displacement volume \\
\hline$\omega$ & Turbine speed \\
\hline$\tau$ & Turbocharger time constant \\
\hline$\eta_{c}$ & Compressor isentropic efficiency \\
\hline$\eta_{t}$ & Turbine isentropic efficiency \\
\hline$\eta_{m}$ & Turbocharger mechanical efficiency \\
\hline$\eta_{v}$ & Volumetric efficiency \\
\hline$\chi_{e g r}$ & EGR valve position \\
\hline$\chi_{v g t}$ & VGT vane position \\
\hline$c_{p}$ & Specific heat at constant pressure, 1.01 \\
\hline$c_{v}$ & Specific heat at constant volume, 0.718 \\
\hline$R_{g}$ & Specific gas constant, $c_{p}-c_{v}$ \\
\hline$\gamma$ & Specific heat ratio, $c_{p} / c_{v}$ \\
\hline$\mu$ & $(\gamma-1) / \gamma$ \\
\hline
\end{tabular}

Table 1. Nomenclature Variable Description

where $P_{b l}$ and $P_{w l}$ are the power to overcome bearing losses and windage losses, respectively. The mechanical efficiency $\eta_{m}$ is introduced to quantify the energy losses. Therefore, (3) can be represented as

$$
\dot{P}_{c}=\frac{1}{\tau}\left(\eta_{m}\left(P_{t}+P_{e m}\right)-P_{c}\right)
$$

$W_{c}$ is related to $P_{c}$ by

$$
W_{c}=\frac{\eta_{c}}{c_{p} T_{a}} \frac{P_{c}}{\left(\frac{p_{\text {in }}}{p_{\text {am }}}\right)^{\mu}-1}
$$


while $P_{t}$ can be expressed by $W_{t}$ :

$$
P_{t}=\eta_{t} c_{p} T_{e x h}\left(1-\left(\frac{p_{a m}}{p_{e x h}}\right)^{\mu}\right) W_{t}
$$

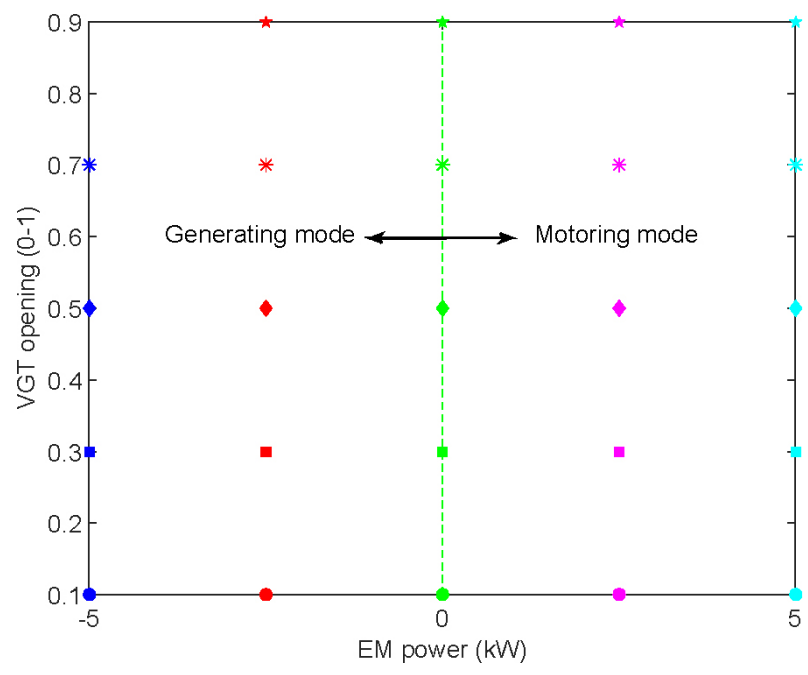

a. The setting on $\chi_{v g t}$ and $P_{e m}$

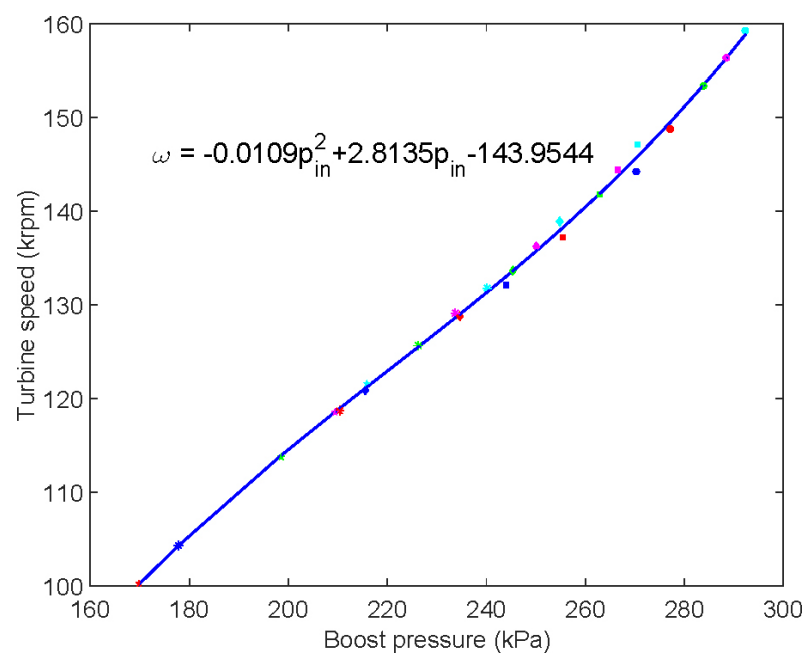

b. Fitting polynomial between $p_{\text {in }}$ and $\omega$

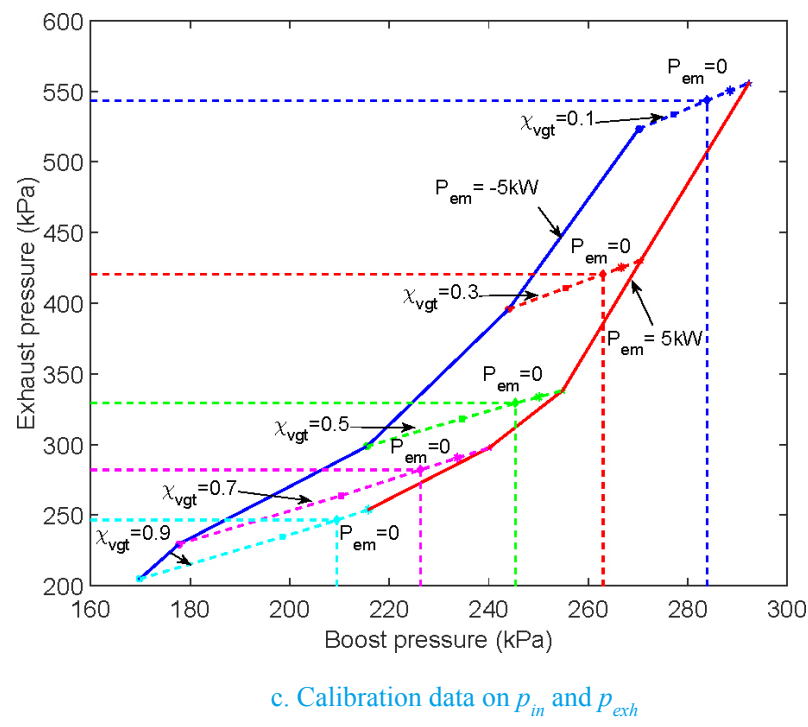

Figure 2. Calibration data by regulating $\chi_{v g t}$ and $P_{e m}$

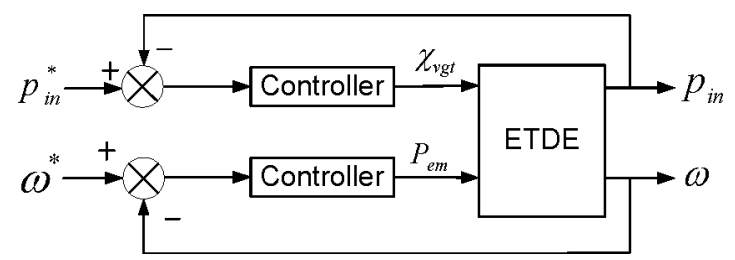

Figure 3. Supposed control structure on boost pressure and turbine speed

\section{Control-Oriented Dynamics Analysis}

The key to reducing exhaust emissions in terms of $\mathrm{NO}_{\mathrm{x}}$ and $\mathrm{PM}$ is keeping rational values of $F_{1}$ and $\lambda$, which can be obtained from the independent variables $W_{c}$ and $W_{\text {egr }}$ according to the expressions in Table 1. From (1a), the independent variables can also be replaced by $p_{\text {in }}$ and $W_{\text {egr }}$. However, to achieve a more integrated target containing fuel efficiency and exhaust emissions, $p_{i n}$ and $W_{\text {egr }}$ are not enough. Since the EM impacts the exhaust manifold dynamics directly, a performance variable in the exhaust manifold has to be considered. However, the explicit principle in selecting outputs of an ETDE and the analysis of its influence on optimization problem and control performance is not found in open literature.

A criteria in selecting control variables is that they cannot be strong correlated, which gives them the feasibility to vary in a zone by regulating actuators. To analyze the relationship between different control variables, a calibration is implemented on a physical diesel engine model at $1800 \mathrm{rpm}, 600 \mathrm{Nm}$ by tuning $\chi_{\text {vgt }}$ and $P_{e m}$, where the results are illustrated in Fig. 2, while the EGR is shut off. The setting on $\chi_{v g t}$ and $P_{e m}$ is shown as Fig. 2(a), where $P_{e m}$ changes from the maximum generating power to the maximum motoring power, with the value of $-5 \mathrm{~kW}$ and $5 \mathrm{~kW}$, respectively. The $\chi_{\text {vgt }}$ changes from 0.1 to 0.9 , where 0 implies the VGT vane is fully closed and offers the maximum assistance to the compressor. Fig. 2(b) shows the strong coupling between boost pressure and turbine speed. The turbine speed behaves as a 2 nd-order polynomial function with the boost pressure, which restricts the tuning flexibility in the exhaust manifold. However, the strong coupling also implies the turbine speed can be shifted by the EM in transients to obtain the most efficient boost. On the other hand, the exhaust pressure varies much according to different settings on $\chi_{\text {vgt }}$, as shown in Fig. 2(c). With the VGT vane closing from 0.9 to 0.1 , both boost pressure and exhaust pressure go up, as well as the condition when $P_{e m}$ increases with the fixed $\chi_{v g t}$.

The coupling between boost pressure and turbine speed can also be interpreted from theoretical analysis. A supposed 2 inputs -2 outputs control structure is illustrated as Fig. 3 , where boost pressure and turbine speed are controlled by VGT and EM, respectively. If the desired turbine speed $\omega^{*}$ increases, the EM power $P_{e m}$ would increase accordingly to drive up $\omega$. At the mean time, $p_{\text {in }}$ would be driven up because of the enhanced boost assist. To keep the tracking on unchanged $p_{i n,}^{*} \chi_{v g t}$ would open further to reduce $p_{i n}$. As a result, $\omega$ is decreased for the less pressure ratio in exhaust manifold. Therefore, $\omega$ has a strong coupling with $p_{\text {in }}$ and its setpoint cannot be selected independently. Based on both test results and dynamics analysis, $p_{e x h}$ is selected as the control variable, together with $p_{i n}$ and $W_{\text {egr }}$. 


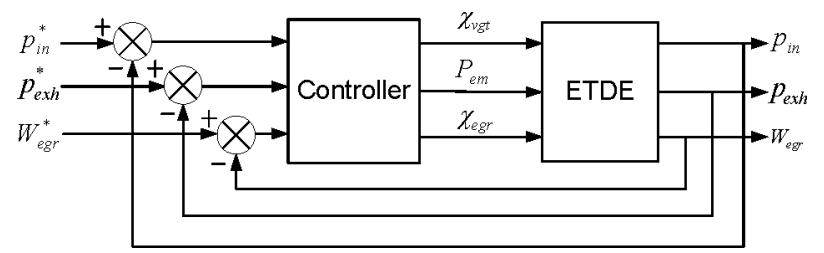

Figure 4. Control structure of the ETDE

\section{Decoupling Controller Design}

The single-input single-output (SISO) PI controllers are widely used in the control of conventional turbocharged diesel engines, while $p_{\text {in }}$ and $W_{\text {egr }}$ are controlled by $\chi_{\text {vgt }}$ and $\chi_{\text {egr }}$, respectively. The gain values of PI controllers are tuned in off-line calibration. However, in the ETDE, the dynamics has been significantly changed, therefore the controllers are to be re-designed. Since it is time-consuming to re-tune the gain values manually, designing a decoupling MIMO controller is critical. The control inputs and measured outputs are selected as

$$
\begin{aligned}
& u=\left[\begin{array}{lll}
\chi_{v g t} & P_{\text {em }} & \chi_{\text {egr }}
\end{array}\right]^{\mathrm{T}}, \\
& y=\left[\begin{array}{lll}
p_{\text {in }} & p_{\text {exh }} & W_{\text {egr }}
\end{array}\right]^{\mathrm{T}} .
\end{aligned}
$$

The 3-inputs 3-outputs control structure of the ETDE is illustrated as Fig. 4.

The ETDE model is formed by the state space equations:

$$
\left[\begin{array}{c}
\dot{x} \\
z \\
y
\end{array}\right]=\left[\begin{array}{ccc}
A & B_{1} & B_{2} \\
C_{1} & D_{11} & D_{12} \\
C_{2} & D_{21} & D_{22}
\end{array}\right]\left[\begin{array}{l}
x \\
w \\
u
\end{array}\right],
$$

where $x \in \mathrm{R}^{n}$ is the state vector, $u$ and $y$ have been defined in (8). Moreover, $w \in \mathrm{R}^{m_{1}}$ is the vector of exogenous inputs, $z \in \mathrm{R}^{p 1}$ is the vector of regulated outputs. In the proposed ETDE control, $w$ and $z$ are defined as

$$
w=\left[\Delta N, \quad \Delta T_{L}\right]^{\mathrm{T}}
$$

and

$$
z=\left[\Delta p_{i n}, \quad \Delta p_{e x h}, \quad \Delta W_{e g r}\right]^{\mathrm{T}}
$$

where $\Delta N$ and $\Delta T_{L}$ denote the disturbances on $N$ and $T_{L} ; \Delta p_{i n}, \Delta p_{e x h}$, $\Delta W_{\text {egr }}$ denote the variations on $p_{i n}, p_{\text {exh }}$, and $W_{\text {egr }}$ introduced by $w$, respectively.

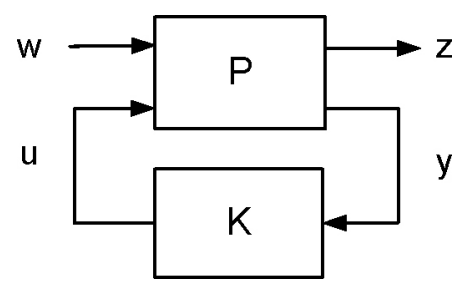

Figure 5. Controller blocks diagram
The full-order controller blocks diagram and the control implementation structure on the ETDE are illustrated as Fig. 5, while the dynamic output feedback control law $u=K(s) y$ is to be designed. A nonsmooth $H_{\infty}$ synthesis method is employed to build $u$ since it is very convenient in practice [12]. This method can address a mixed set of time- and frequency- domain criteria including settling time, steady state error, stability margin, and noise rejection. The constraints can be grouped as hard (must have) constraints and soft (nice to have) objectives. The controller synthesis is transformed to an optimization problem as

$$
\underset{g}{\operatorname{minimize}}: \max _{i}\left\{\left\|T_{w_{i} \rightarrow z_{i}}(P, K)\right\|\right\},
$$

$$
\text { subject to : } \max _{j}\left\{\left\|T_{w_{j} \rightarrow z_{j}}(P, K)\right\|\right\} \leq 1 \text {, }
$$

where $g$ is the vector of tunable gain values, $\left\|T_{w \rightarrow z}\right\|$ denotes the closed loop map from input $w$ to output $z$, and $\| \bullet$ can be either $H_{\infty}$ norm or $H_{2}$ norm, $i$ and $j$ denote the index of soft objectives and hard constraints, respectively. The optimization problem (11) and (12) means to minimize the worst-case value of the soft objectives while satisfying all the hard constraints. In the formulation, all terms have been normalized [13].

In this research, the soft objectives are settling time and steady state error. The hard constraints are stability margins including the gain margin and phase margin. The coefficient matrices in (8) are obtained via calibration tests. The systune solver in Matlab is adopted to compute the decoupling control law [14] .

\section{Simulation Results}

Simulations have been carried out on a physical plant model built in Dynasty, a proprietary multi physics simulation software package used within Caterpillar. The engine manifolds are modeled as one-dimensional components, permitting to capture the pulsations caused by engine actuators operation. All the cylinders are modeled separately to indicate the energy transfer from engine to turbocharger, such that the transient performance is simulated accurately.

The compressor and turbine are represented as map based models. The EM is also represented as a map-based model, whose maximum motoring/generating power are found from a two-dimensional map, with the inputs of $\omega$ and power electronics controller setting. The controllers are built in Matlab/Simulink for the available tools in Mat-lab can facilitate the controller design. To guarantee steady communications, the sampling frequency of the controller in Matlab and the controlled plant in Dynasty are set as identical. The investigated engine is a six-cylinder, 7.01-Liter heavy duty engine with rated power of $225 \mathrm{~kW}$ at $2200 \mathrm{rpm}$ and a rated torque of 1280 $\mathrm{Nm}$ at $1400 \mathrm{rpm}$. The engine has been fitted with an experimental turbo-charger for the purposes of this work. The maps used in the paper are all generated from off-line experimental calibration on the instrumented engine. 


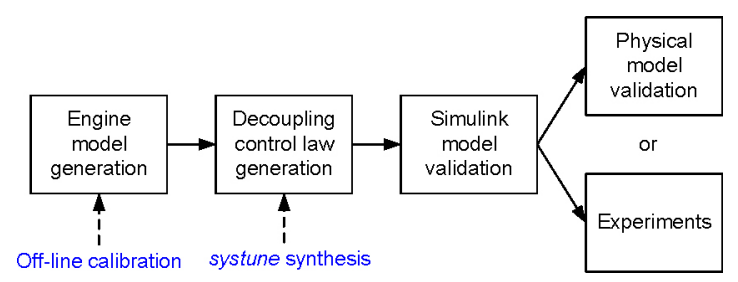

Figure 6. Workflow in developing decoupling controller for the ETDE

Prior to the physical simulation, the decoupling control law has been validated in the Simulink model, while the engine model is built from the off-line engine calibration data. Generally speaking, the workflow of this paper can be illustrated as Fig. 6. The simulations on Simulink and Dynasty are both implemented. The operating points are selected as $1800 \mathrm{rpm}, 260 \mathrm{Nm}$, and $1800 \mathrm{rpm}, 815 \mathrm{Nm}$, covering the low load region and high load region, which are typical working conditions in the trenching test cycle for heavy duty engines. A block load condition between the switching of the two operating points is also given, while the gain values are scheduled according to the load.

\section{Simulation in Simulink}

In the Simulink simulation, both the controller and the ETDE model are built in Simulink, as shown in Fig. 7. In generating the decoupling control law, the criteria are to be specified. In the soft objectives, the criteria on settling time and steady state error are set as $1 \mathrm{~s}$ and $0.5 \%$, respectively. In the hard constraints, the criteria on gain margin and phase margin are set as $3 \mathrm{~dB}$ and $5 \mathrm{rad} / \mathrm{s}$, respectively. At the operating point of $1800 \mathrm{rpm}, 260 \mathrm{Nm}$, the setpoints on $p_{\text {in }}$ and $W_{\text {egr }}$ are set as $170 \mathrm{kPa}$ and $0.03 \mathrm{~kg} / \mathrm{s}$, respectively, while the setpoint on $p_{\text {exh }}$ changes as a sequence of step-changed values between $220 \mathrm{kPa}$ and $250 \mathrm{kPa}$. It can be observed from Fig. 8 that the tracking on all the three variables is fast and smooth.

Similarly, the simulation results at $1800 \mathrm{rpm}, 700 \mathrm{Nm}$ are shown as Fig. 9. The setpoints on $p_{\text {in }}$ and $W_{\text {egr }}$ are set as $240 \mathrm{kPa}$ and $0.05 \mathrm{~kg} / \mathrm{s}$, respectively, while the setpoint on $p_{e x h}$ changes as a sequence of step-changed values between $260 \mathrm{kPa}$ and $280 \mathrm{kPa}$. The tracking performance is still very fast and accurate.

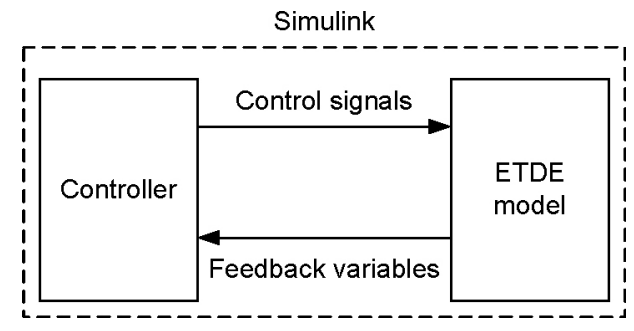

Figure 7. System layout in Simulink simulation
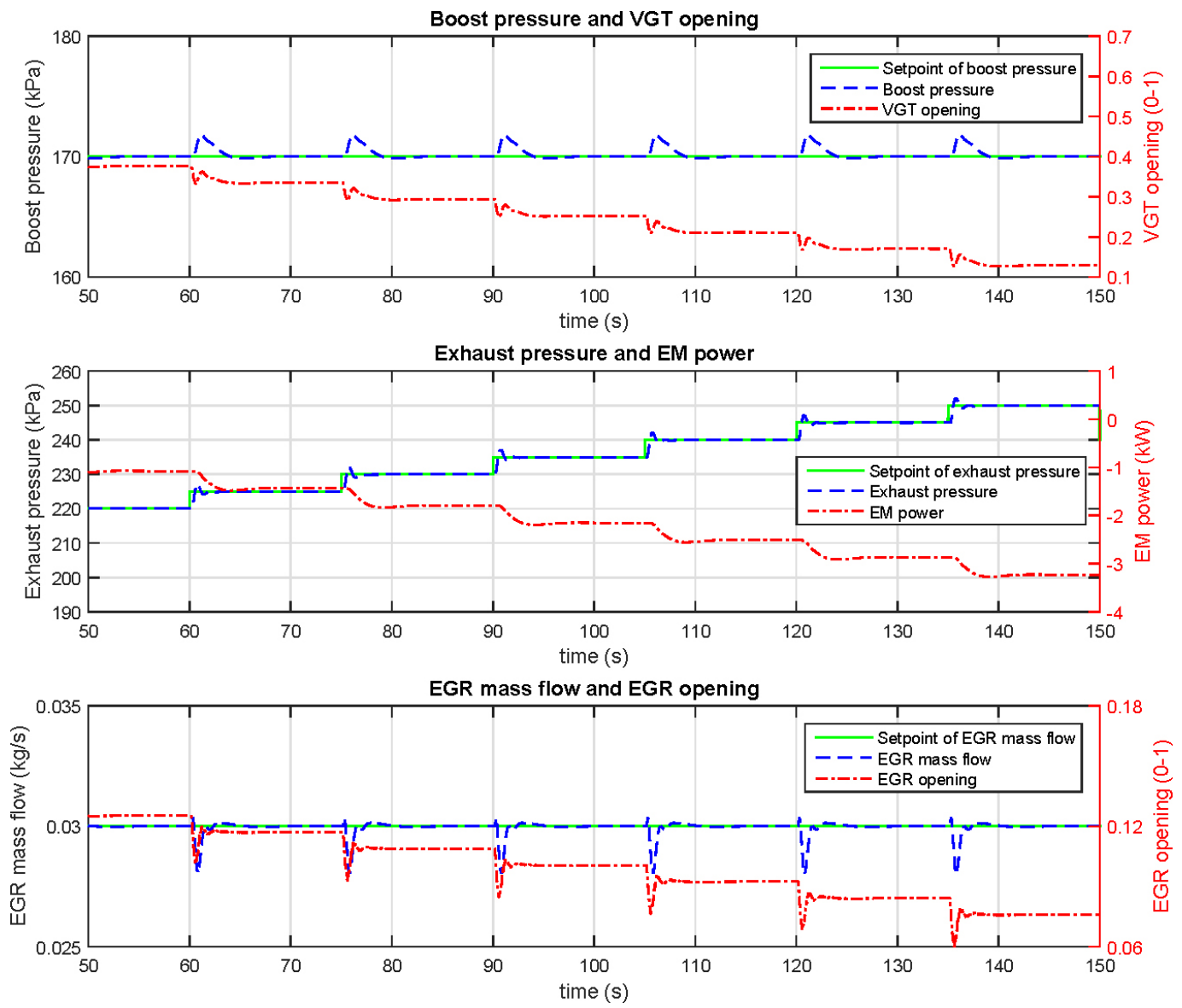

Figure 8. Simulation results at $1800 \mathrm{rpm}, 260 \mathrm{Nm}$ in Simulink 
Boost pressure and VGT opening

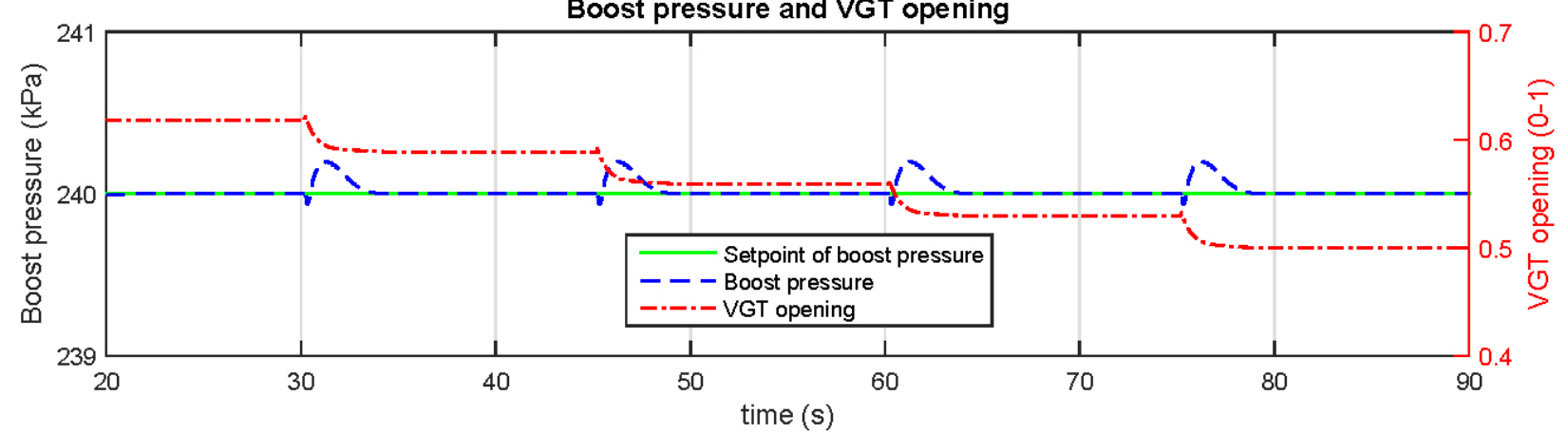

Exhaust pressure and EM power
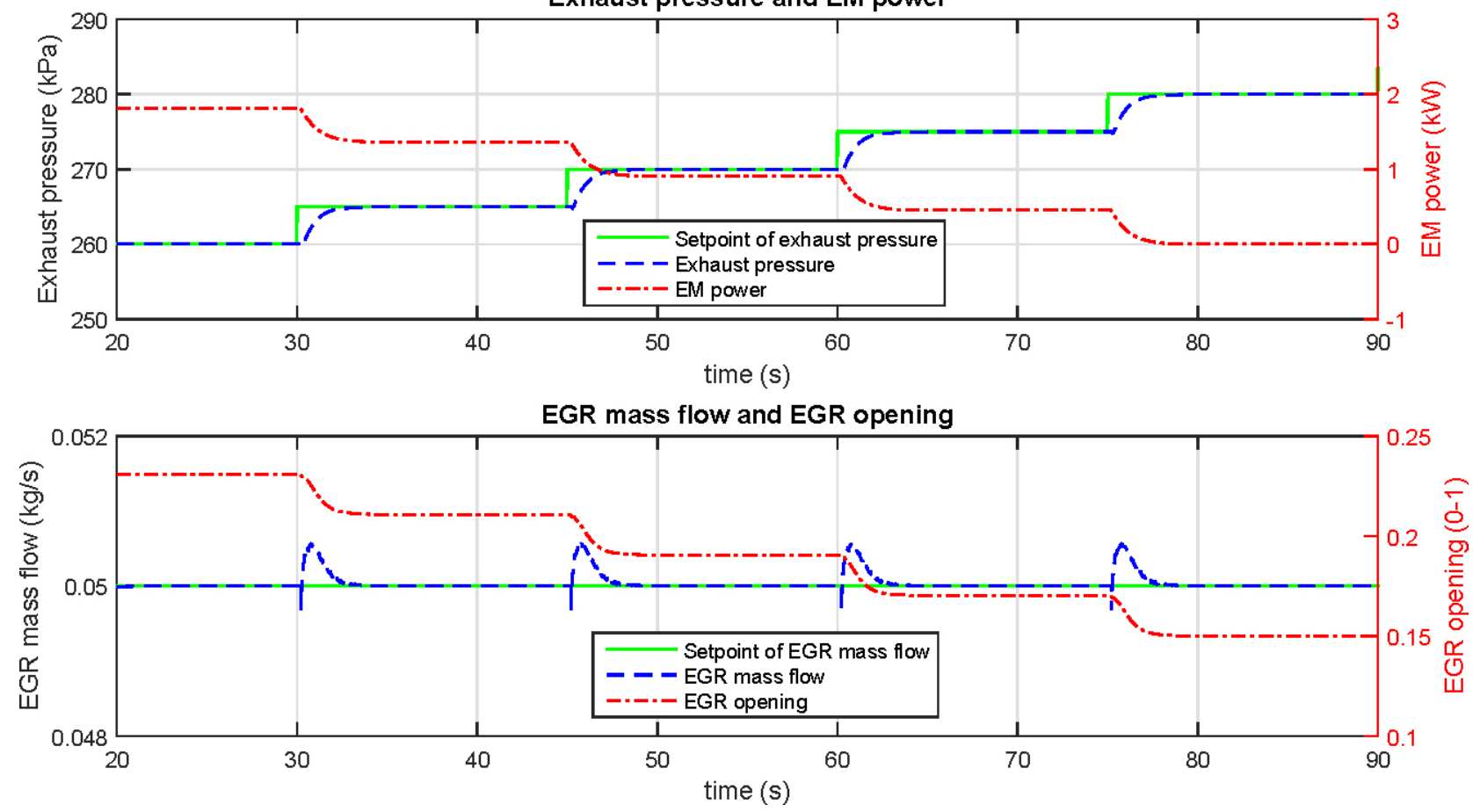

Figure 9. Simulation results at $1800 \mathrm{rpm}, 700 \mathrm{Nm}$ in Simulink

\section{Simulation in Dynasty}

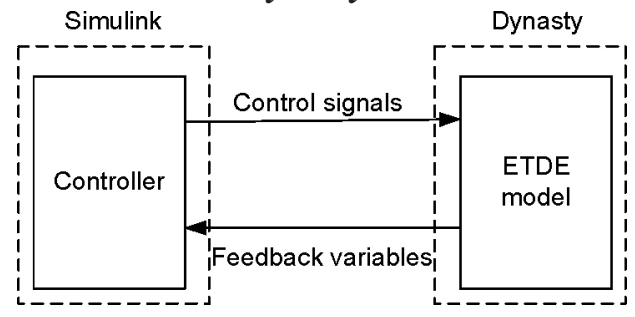

Figure 10. System layout in Dynasty simulation

In the Dynasty simulation, the controller and ETDE model are built in Simulink and Dynasty, respectively, as shown in Fig. 10. As a comparison, the simulation results at $1800 \mathrm{rpm}, 260 \mathrm{Nm}$ and $1800 \mathrm{rpm}$, $700 \mathrm{Nm}$ in Dynasty are illustrated in Fig. 11 and Fig. 12, respectively. The setpoint on $p_{e x h}$ is kept as the same in Simulink simulation. To reveal the engine dynamics better, the setpoints on $p_{\text {in }}$ and $W_{\text {egr }}$ are generated from the embedded setpoints maps in the engine control unit (ECU). The tracking performance is still very desirable.

The controller is also tested under block loads, where the engine operating point switches between $1800 \mathrm{rpm}, 700 \mathrm{Nm}$, and $1800 \mathrm{rpm}$, $260 \mathrm{Nm}$, alternatively. The transient period is 1s. The operating conditions are demonstrated as Fig. 13, where the block load condition repeats 4 cycles. In each cycle, the setpoint of $p_{\text {exh }}$ at 1800 rpm, $700 \mathrm{Nm}$ is set as $265 \mathrm{kPa}, 270 \mathrm{kPa}, 275 \mathrm{kPa}$, and $280 \mathrm{kPa}$, respectively. Meanwhile, the setpoint of $p_{\text {exh }}$ at $1800 \mathrm{rpm}, 260 \mathrm{Nm}$ is kept as $215 \mathrm{kPa}$ in each cycle. The setpoints of $p_{\text {in }}$ and $W_{\text {egr }}$ are generated from ECU. The tracking of the control variables in transients is very fast with small spikes, as can be observed in Fig. $\underline{14}$. The employed decoupling controller only need to schedule gain values rather than the system model when operating point changes, which reduces the risk of system instability. 

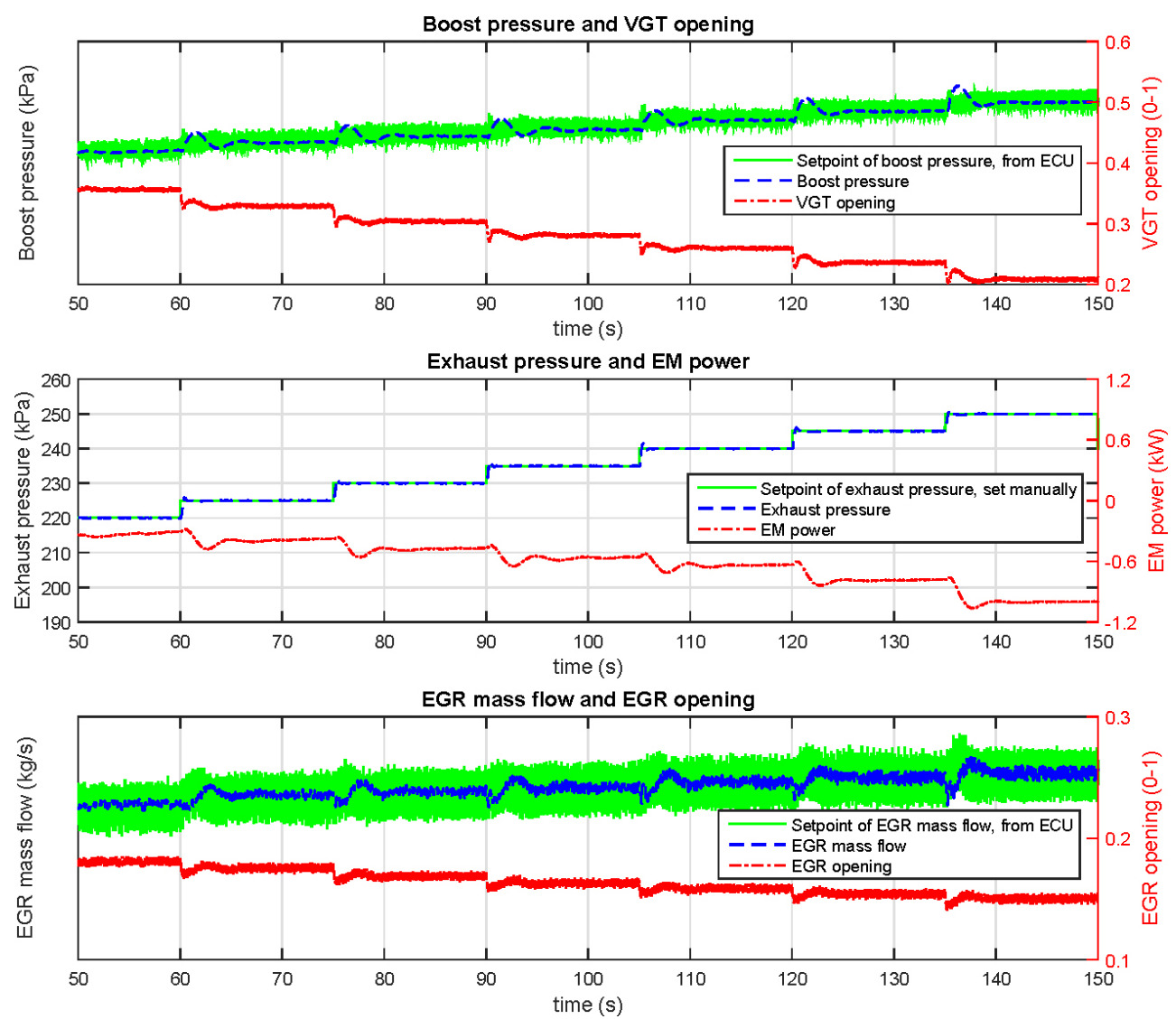

Figure 11. Simulation results at $1800 \mathrm{rpm}, 260 \mathrm{Nm}$ in Dynasty
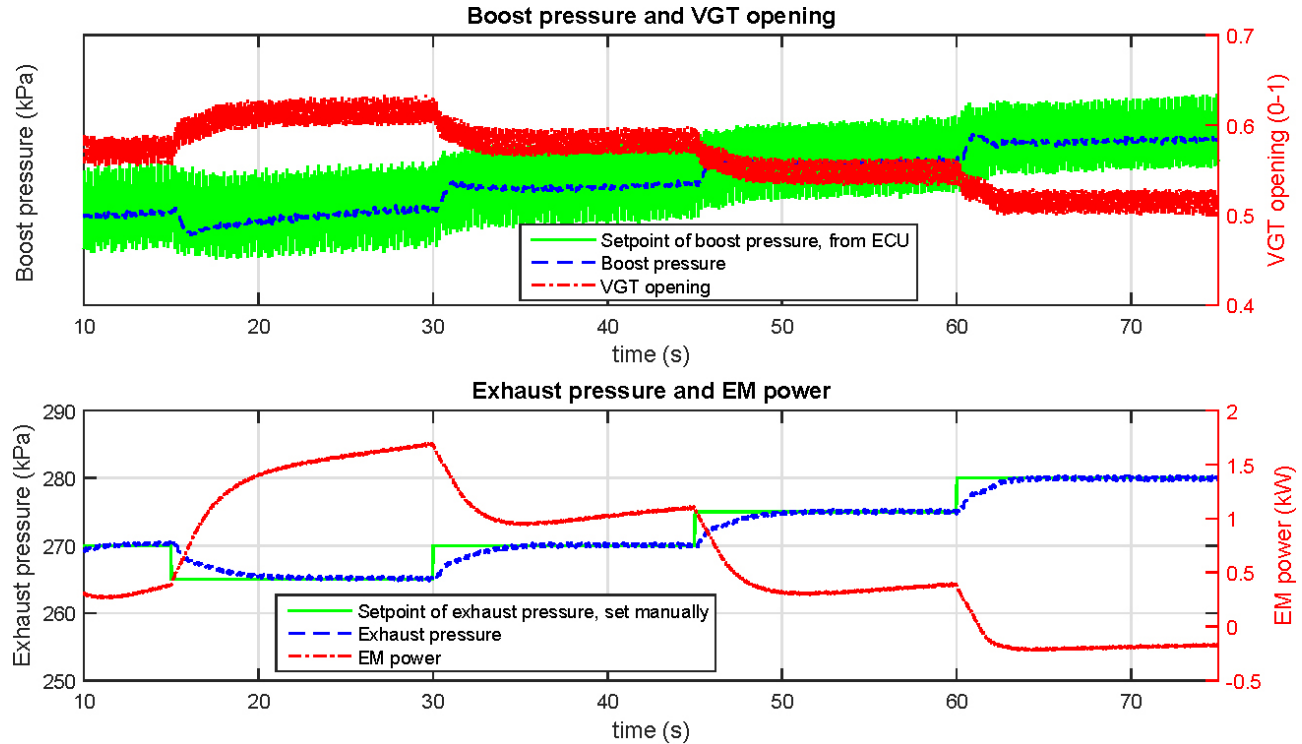

EGR mass flow and EGR opening

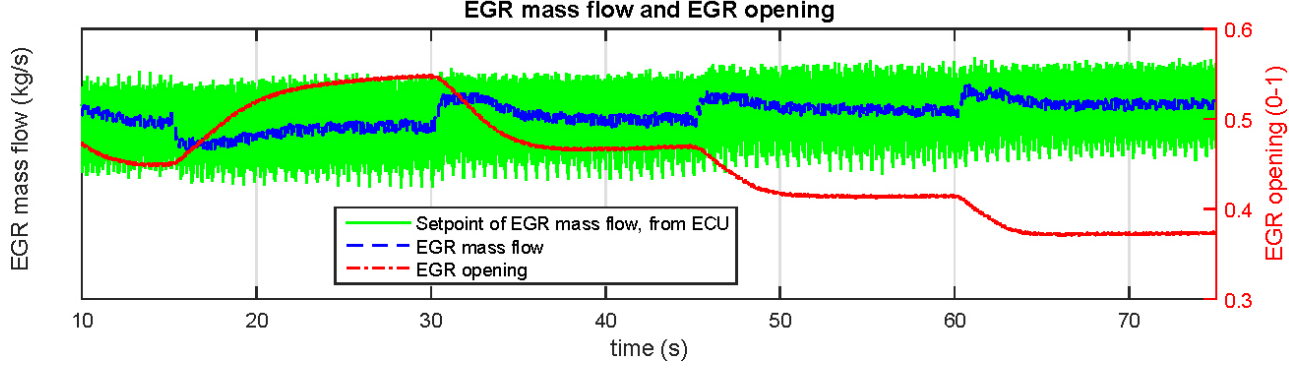

Figure 12. Simulation results at $1800 \mathrm{rpm}, 700 \mathrm{Nm}$ in Dynasty 

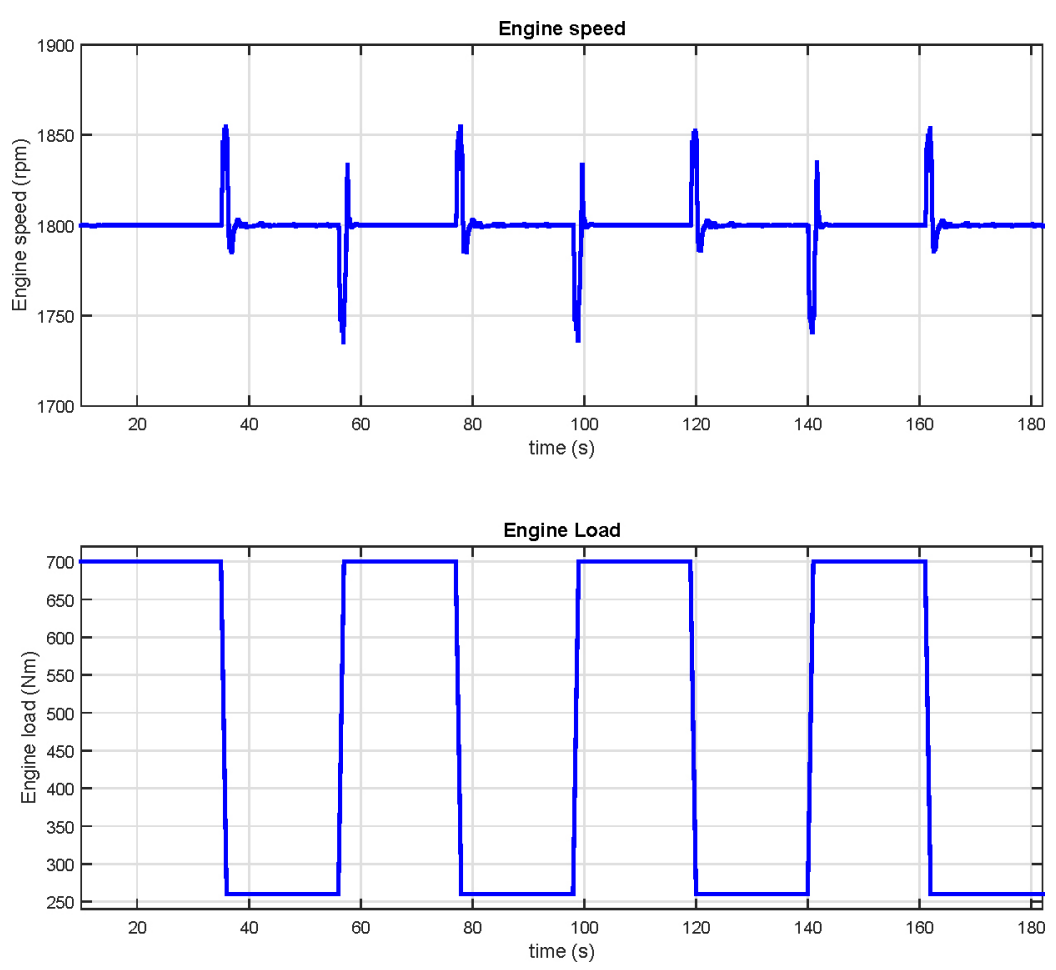

Figure 13. Operating points at block loads
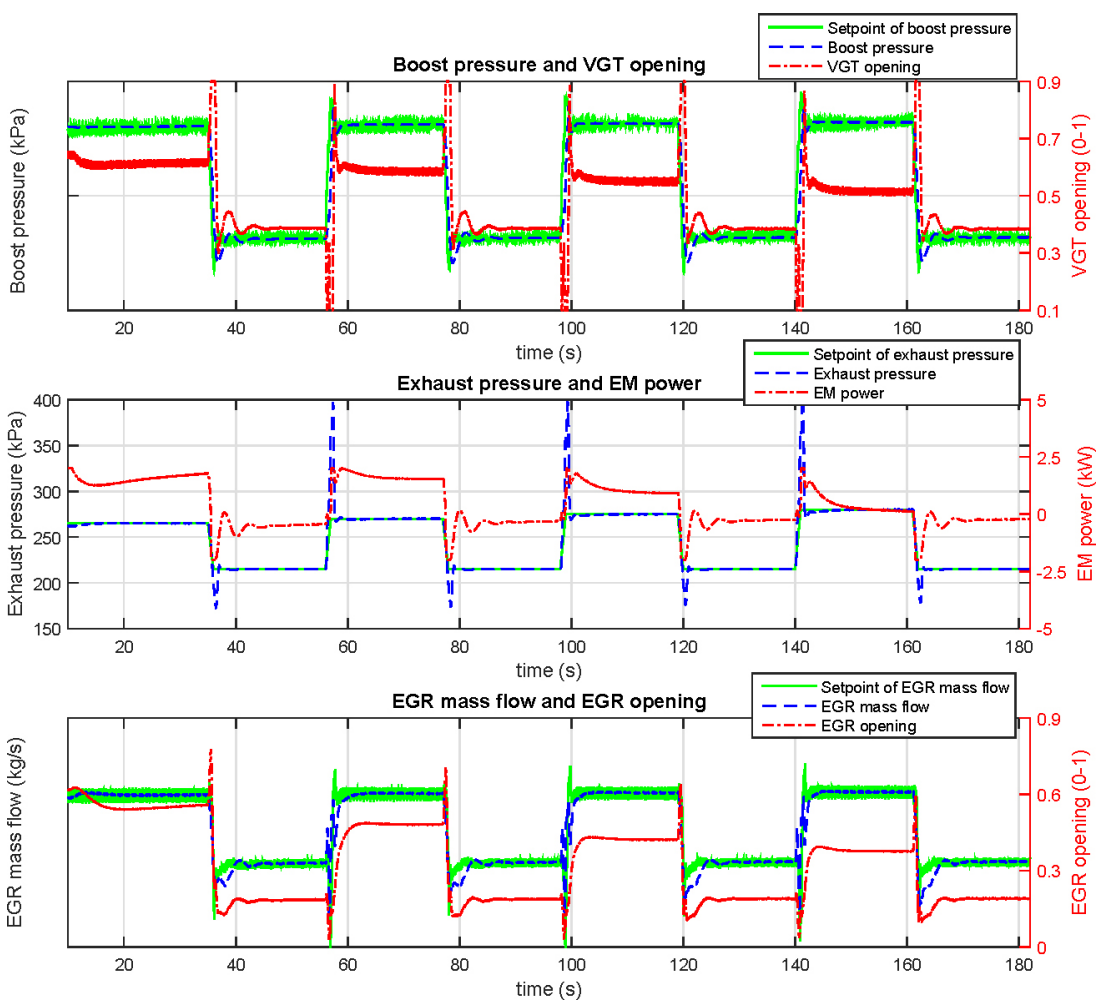

Figure 14. Simulation results at block loads in Dynasty

\section{Conclusion}

The control-oriented dynamics analysis and a model-based MIMO decoupling controller for the ETDE are proposed in this paper. In generating the control law, both the requirements on tracking performance and stability margins are considered. The selection of control inputs and control outputs is based on concrete dynamics analysis. Simulation results on both Simulink model and physical model are all given. The next stage work is to apply the designed decoupling controller for real-time fuel economy optimization of ETDE.

\section{References}

1. Reduction and testing of greenhouse gas (GHG) emissions from heavy duty vehicles - Lot 1: Strategy, Ricardo plc, UK, 2011. 
2. Martinez-Botas, R., Apostolos, P., and Yang, M., "'Overview of boosting options for future downsized engines," Science China Technological Sciences 54, no. 2 (2011): 318-331.

3. Yamashita, Y., Ibaraki, S., Sumida, K., and Ebisu, M. et al., "Development of electric supercharger to facilitate the downsizing of automobile engines," Mitsubishi Heavy Industries Technical Review 47, no. 4 (2010): 7-12.

4. Bailey, M., "Electrically Assisted Turbo-Charger Development for Performance and Emissions," in Diesel Engine Emissions Reduction Conference, San Diego, p. 58. 2000.

5. Arnold, S., Balis, C., Barthelet, P., Poix, E., et al., "Garrett Electric Boosting Systems (EBS) Program," Honeywell Inc, 2005.

6. Ibaraki, S., Yamashita, Y., Sumida, K., Ogita, H. et al., "Development of the Hybrid Turbo, an Electrically Assisted Turbocharger," Mitsubishi Heavy Ind. Tech. Rev 43, no. 3 (2006): 1-5.

7. Terdich, N., Martinez-Botas, R., Howey, D., Copeland, C. et al., "Off-Road Diesel Engine Transient Response Improvement by Electrically Assisted Turbocharging," SAE Technical Paper 2011-24-0127, 2011, doi:10.4271/2011-24-0127.

8. Terdich, N. and Martinez-Botas, R., "Experimental Efficiency Characterization of an Electrically Assisted Turbocharger," SAE Technical Paper 2013-24-0122, 2013, doi:10.4271/2013-24$\underline{0122}$.

9. Glenn, BC., Upadhyay, D., and Washington, G., "Control design of electrically assisted boosting systems for diesel powertrain applications," IEEE Transactions on Control Systems Technology 18, no. 4 (2010): 769-778.

10. Bilgin, B., Magne, P., Malysz, P., Yang, Y. et al., "Making the Case for Electrified Transportation," IEEE Transactions on Transportation Electrification 1, no. 1 (2015): 4-17.

11. Jankovic, M., and Kolmanovsky, I.. "Constructive Lyapunov control design for turbocharged diesel engines," IEEE Transactions on Control Systems Technology 8, no. 2 (2000): 288-299.
12. Apkarian, P., and Noll, D., "Nonsmooth $H_{\infty}$ synthesis," IEEE Transactions on Automatic Control 51, no. 1 (2006): 71-86.

13. Apkarian, P., "Tuning controllers against multiple design requirements," in Proceedings of the American Control Conference, 3888-3893, 2014.

14. Robust Control Toolbox. Natick, MA, USA: Math-Works, 2015.

\section{Contact Information}

Dr Dezong Zhao

Department of Aeronautical and Automotive Engineering Loughborough University

Leicestershire

UK

d.zhao2@1boro.ac.uk

Professor Richard Stobart

Department of Aeronautical and Automotive Engineering Loughborough University

Leicestershire

UK

r.k.stobart@lboro.ac.uk

\section{Acknowledgment}

This work was co-funded by the Technology Strategy Board (TSB) UK, under a grant for the Low Carbon Vehicle IDP4 Programme (TP14/LCV/6/I/BG011L). The Technology Strategy Board is an executive body established by the United Kingdom Government to drive innovation. It promotes and invests in research, development and the exploitation of science, technology and new ideas for the benefit of business - increasing sustainable economic growth in the UK and improving quality of life.

Thanks also go to our consortium partners and subcontractors.

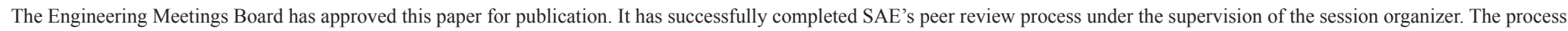
requires a minimum of three (3) reviews by industry experts.

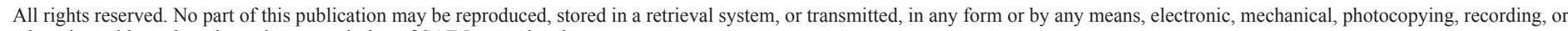
otherwise, without the prior written permission of SAE International.

Positions and opinions advanced in this paper are those of the author(s) and not necessarily those of SAE International. The author is solely responsible for the content of the paper.

ISSN 0148-7191

http://papers.sae.org/2016-01-0617 